ACCEPTED MANUSCRIPT

\title{
Magnetic tracking of gastrointestinal motility
}

To cite this article before publication: Christian Emil Brinck et al 2020 Physiol. Meas. in press https://doi.org/10.1088/1361-6579/abcd1e

\section{Manuscript version: Accepted Manuscript}

Accepted Manuscript is "the version of the article accepted for publication including all changes made as a result of the peer review process, and which may also include the addition to the article by IOP Publishing of a header, an article ID, a cover sheet and/or an 'Accepted Manuscript' watermark, but excluding any other editing, typesetting or other changes made by IOP Publishing and/or its licensors"

This Accepted Manuscript is @ 2020 Institute of Physics and Engineering in Medicine.

During the embargo period (the 12 month period from the publication of the Version of Record of this article), the Accepted Manuscript is fully protected by copyright and cannot be reused or reposted elsewhere.

As the Version of Record of this article is going to be / has been published on a subscription basis, this Accepted Manuscript is available for reuse under a CC BY-NC-ND 3.0 licence after the 12 month embargo period.

After the embargo period, everyone is permitted to use copy and redistribute this article for non-commercial purposes only, provided that they adhere to all the terms of the licence https://creativecommons.org/licences/by-nc-nd/3.0

Although reasonable endeavours have been taken to obtain all necessary permissions from third parties to include their copyrighted content within this article, their full citation and copyright line may not be present in this Accepted Manuscript version. Before using any content from this article, please refer to the Version of Record on IOPscience once published for full citation and copyright details, as permissions will likely be required. All third party content is fully copyright protected, unless specifically stated otherwise in the figure caption in the Version of Record.

View the article online for updates and enhancements. 


\title{
Magnetic tracking of gastrointestinal motility
}

\author{
Authors \\ Christian Emil Brinck ${ }^{1,2}$, Esben Bolvig Mark ${ }^{3}$, Mette Winther Klinge ${ }^{1}$, Cecilie Ejerskov ${ }^{2}$, Nanna Sutter ${ }^{1}$, \\ Vincent Schlageter ${ }^{4}$, S. Mark Scott ${ }^{5}$, Asbjørn Mohr Drewes ${ }^{3}$, Klaus Krogh ${ }^{1,6}$ \\ Affiliations \\ 1: Department of Hepatology and Gastroenterology, Aarhus University Hospital, Aarhus, Denmark \\ 2: Department of Pediatrics and Adolescent Medicine, Aarhus University Hospital, Aarhus, Denmark \\ 3: Mech-Sense, Department of Gastroenterology and Hepatology, Aalborg University Hospital, Aalborg, \\ Denmark \\ 4: Motilis Medica SA, Lausanne, Switzerland \\ 5: Neurogastroenterology Group (GI Physiology Unit), Centre for Neuroscience, Surgery \& Trauma, Blizard \\ Institute, Queen Mary University of London, London, UK \\ 6: Steno Diabetes Center Aarhus, Aarhus University Hospital, Aarhus, Denmark
}

\section{Correspondence}

Klaus Krogh, Neurogastroenterology Unit, Department of Hepatology and Gastroenterology, Aarhus University Hospital, Aarhus, Denmark. Email: klaukrog@rm.dk

\section{Keywords}

gastrointestinal motility, magnetic tracking, ingestible capsule, gastrointestinal transit time, colonic transit time, colonic contraction patterns

\section{Acknowledgements}

This publication was partly funded by research grants from The Novonordisk Foundation, Denmark; The Danish Children's Cancer Foundation (“Børnecancerfonden”), Denmark; The Louis-Hansen Foundation, Denmark; The Ronald McDonald Children's Foundation, Denmark. Vincent Schlageter is co-owner of Motilis Medica SA. All other authors have no conflicts of interest to disclose. 


\section{Abbreviations}

$\mathrm{GI}$ = gastrointestinal, $\mathrm{HRM}=$ high resolution manometry, $\mathrm{MRI}=$ magnetic resonance imaging, $\mathrm{MTS}-1=$ motility tracking system-1, 3D-Transit = Motilis 3D-Transit system, ROM = radio-opaque markers, WMC $=$ wireless motility capsule, DM-1 = type 1 diabetes mellitus

\section{Abstract}

Objective: Capsule-based methods for assessment of gastrointestinal (GI) motility have seen great improvements in recent decades. The most recent development is the electromagnetic Motilis 3D-Transit system (3D-Transit). The aim of this paper is to review and discuss the development and technical properties of magnetic tracking of GI motility.

Approach: We performed a comprehensive literature review on magnetic tracking in $\mathrm{Gl}$ research.

Main results: The Motility Tracking System was the first capsule based magnetic system to be used in GI motility research. However, the potential of the system was hampered by its stationary and hospitalizing nature. This led to the development of the electromagnetic Motilis 3D-Transit system. The 3D-Transit system is a portable system that allows for assessment of both whole gut and regional transit times and contraction patterns in a fully ambulatory setting in the patients' home environment with only minor restrictions on movements. The spatiotemporal resolution of 3D-Transit allows assessment of segmental colonic transit times and permits an analysis of gastric and colonic movements with a degree of detail unrivalled by other ambulatory methods, such as the Wireless Motility Capsule. Recently, robust normative data on 3D-Transit have been published.

Significance: This review provides a current perspective on the use of capsule-based magnetic tracking systems in GI research and how they represent a potentially valuable clinical resource for GI physicians and in GI research. 


\section{Introduction}

Gastrointestinal (GI) motility is a product of numerous and sophisticated autonomic functions. These include hormonal, muscular, and myoelectrical mechanisms. The interstitial cells of Cajal are responsible for the phasic contractile activity of the GI tract, by spontaneous generation of slow waves that spread throughout the smooth muscle cells of GI wall [1]. Disorders of GI motility, such as gastroparesis, constipation, and the irritable bowel syndrome occur when these critical controlling mechanisms of GI motility may not function properly. They affect up to one-third of the general population, and constitute a significant healthcare and socioeconomic burden and cause substantial decrease in quality of life of those affected [2-4]. GI dysmotility manifests as abdominal pain, nausea, bloating, vomiting, diarrhea, as well as infrequent and incomplete rectal evacuation $[5,6]$. Such symptoms are often associated with delayed or accelerated GI transit or uncoordinated peristaltic activity in one or more segments of the GI tract $[7,8]$.

Motility assessment of the gut is usually performed either by measuring transit times (indices of content flow in the GI tract) or pressure amplitudes and frequencies (indices of GI contractions) [9]. Myoelectrical activity of the GI tract can be measured non-invasively using dense arrays of electrodes like the electrogastrography method for gastric evaluation and high-resolution electrical mapping for the remaining $\mathrm{Gl}$ tract $[10,11]$.

Established and emerging methods for evaluation of GI motility are listed in Table 1. Principal methods for the evaluation of motility in the stomach and duodenum are primarily scintigraphic gastric emptying (GE), antroduodenal manometry, and the wireless motility capsule (WMC; SmartPill ${ }^{\mathrm{TM}}$, Medtronic, MN, USA) $[12,13]$. Principal methods for evaluation of motility in the small intestine and/or colon include antropyloroduodenojunal manometry, hydrogen breath tests, radio-opaque markers (ROM), colonic scintigraphy and colonic manometry [14-18]. All these methods are well established in clinical practice, but all have their recognized limitations (Table 1). For example, the ROM method for assessing whole gut transit lacks standardization, depends on the compliance of the patient, and exposes the subject under study to ionizing radiation. Moreover, it only gives a rough temporal estimate of the transit time through the intestines [19]. Hydrogen breath tests are subject to several sources of error, as small bowel bacterial overgrowth is associated with motility abnormalities and lactulose markedly accelerates transit of the small intestine $[9,20]$. Scintigraphy is expensive, time-consuming, involves exposure to radiation, and is restricted to specialized centers [21]. More importantly, these methods only provide snapshots of GI transit rather than single continuous measurements [9]. High resolution manometry (HRM) provides continuous recording of GI pressure waves within a specific region of the GI tract, usually the esophagus, antroduodenal region, or the distal colon and rectum. HRM, however, is invasive, time-consuming, and require specialized centers because of high technical requirements [9]. 
Magnetic resonance imaging (MRI) is an emerging technique for assessment of small intestinal [22] and colonic [23] contractions as well as orocecal and whole-gut transit times [24]. Unfortunately, MRI is costly and does not allow for ambulatory evaluation.

The purpose of this topical review is to outline the current use of magnetic tracking in GI research. Accordingly, we conducted a comprehensive search (March $1^{\text {st }} 2020$ ) in PubMed for the years 1980-2020 using the following search terms: "gastrointestinal motility method", "3D transit", "magnetic tracking", and "motility tracking system". Only papers written in English were included. Reference lists in the papers were read for any missed papers in the search.

— Table 1 near here -

\section{Historical perspective of magnetic tracking in gastrointestinal motility research}

Early studies from the 1990's have used magnetic markers as a non-invasive tool for tracking of movements within the GI tract. Weitschies et al. used the seven channel DC superconducting quantum interference device (Biomagnetic Technologies Inc., San Diego, USA), which consisted of multiple highly sensitive magnetic sensors. The system used magnetically marked pellets enclosed in a cylindrical silicone capsule. The device proved itself accurate, but required a shielded environment and was heavily expensive $[25,26]$.

The MTS- 1 was first described in 2005 by Stathopoulos et al., who demonstrated it possible to obtain a 3D configuration of the gut and dynamics of the magnet displacement (velocity, transit time, length estimation, rhythms) [27]. Hence, the MTS-1 was a promising tool in gastroenterological research. However, it was severely limited by its stationary nature that confined the subject to stay still in a specially designed bed during the entire investigation.

This led to the development of an ambulatory system, 3D-Transit. Though sharing many principal characteristics with MTS-1, 3D-Transit is fundamentally different as it replaces the permanent magnet in the capsule with an electromagnetic transmitter system. 3D-Transit was first described in 2014 by Haase et al., who proved the system feasible in healthy subjects and correlating well with whole gut transit times assessed by ROM [28].

\section{Capsule-based technologies for assessment of gastrointestinal motility}

Over recent decades, there has been a growing interest in capsule-based technologies providing information on whole-gut and regional GI transit times through the tracking of one or more capsules during 
their passage through the GI tract. Such methods may be useful in clinical settings for diagnostic evaluation and management of unexplained GI symptoms or when a generalized or multiregional motility disorder is suspected. Furthermore, they can provide valuable insights into normal and pathological GI physiology [7].

The WMC system is the most used and currently the only commercial available capsule-based system for evaluation of GI motility [29]. It features an ingestible capsule that measures pressure, $\mathrm{pH}$, and temperature as it passes through gut. The WMC system is considered the method of choice in situations where multiregional or whole gut motility disorders are suspected as it allows for ambulatory asșessment of gastric emptying, small intestinal transit time, colorectal transit time, and whole gut transit time [30-33]. The location of the WMC is primarily determined by stereotypical changes in $\mathrm{pH}$ at the pylorus and ileocecal junctions as well as temperature change (drop on expulsion from the body). This enables an assessment of regional gut function (stomach, small bowel, large bowel), but more precise measurement is limited as the capsule location within each GI region is unknown at any time point. Accordingly, detailed information on segmental colonic transit is, for example, not available [29, 34].

The PillCam (Pillcam SB video capsule; Given Imaging, Yokneam, Israel) is an endoscopic capsule system, normally used to diagnose intraluminal epithelial diseases in the small bowel. By means of a computerized endoluminal image analysis of the small bowel, the system allows for detection of wall dynamics and movement of content, and thus provides a noninvasive, simple procedure for automatic identification of intestinal motor dysfunction. Accordingly, the system can automatically discriminate between hypodynamic and hyperdynamic motor disorders, displaying a higher sensitivity than manometry [35-37]. However, the system is currently restricted to research and does not provide any data on GI transit, as with manometry.

The original motility tracking system-1 (MTS-1, MTS Record, Motilis, Lausanne, Switzerland) was developed to allow for detailed spatiotemporal tracking during passage through the GI tract. It consists of a small magnet ( $\varnothing 6 \times 15 \mathrm{~mm}$, weight $0.9 \mathrm{~g}$ ) which is continuously tracked by a stationary detector [27]. The system has been validated and used in several studies to assess GI motility in patients with liver cirrhosis and portal hypertension, cystic fibrosis, neuroendocrine tumors, spinal cord injuries, and systemic sclerosis [38-42]. The major shortcoming of the method is its non-ambulatory nature, requiring the subject under study to be immobile during recordings. The system was last used in a clinical study in 2014 [43] and has been replaced by the newer 3D-transit system (3D-Transit, Motilis Medica SA, Lausanne, Switzerland).

3D-Transit is a completely ambulatory, non-invasive tool to assess both whole-gut and regional transit times as well as movement patterns within the Gl tract. Using a body-worn detection matrix, the system simultaneously tracks the precise position and general orientation of up to three electromagnetic capsules 
from ingestion to expulsion. Given its ambulatory nature and the electromagnetic technology, it is possible to perform the examination in the home environment, under near-normal physiological conditions [28].

\section{General principles of MTS-1 and 3D-Transit}

During recording, an iterative algorithm in the software converts the electromagnetic field into five spatiotemporal coordinates displayed on the computer: three position coordinates $(x, y, z)$ and two angle coordinates $(\theta, \varphi)$ (Figure 1B). The $x, y$, and $z$ represent the three-dimensional spatial position, thus being a reflection of $\mathrm{Gl}$ transit time between two anatomical positions. The $\theta$ and $\varphi$ represent orientation coordinates with respect to the four sensors in the detector, thus being a surrogate measure of contraction frequency. Using the dedicated software, all movements of each capsule are converted into detailed scalar and vectoral representations. Velocity of movements and orientation of the capsules reflect progression dynamics of the luminal content in the GI tract. Changes in position angles reflect contractile activity in the GI tract $[27,44,45]$.

Assessment of regional gastrointestinal motility requires easy interpretation of specific anatomical landmarks. Hence, four landmarks must be recognized: 1) ingestion, 2) pyloric passage, 3) ileocecal passage, and 4) the exit of the capsule. Recognition is carried out by examination of the 2D-plot alongside detection of changes in contraction frequencies (Figure 1B).

Whole gut transit time is defined as the time between capsule ingestion and it being expelled from the body. The latter is confirmed by a centered vertical drop followed by a signal loss from the capsule. The signal loss is due to the capsule having exited the body and thus exceeding the maximum distance to the detector required for connection. This corresponds with time of a bowel movement noted in a diary kept by the subject under study. Gastric emptying time is defined as the time from ingestion of the capsule until pyloric passage. Small intestinal transit time is defined as time from the pyloric passage until ileocecal passage.

Pyloric passage is characterized by cessation of the $3 \mathrm{~min}^{-1}$ contraction frequency typical for the stomach [46], the appearance of the duodenal arch, and the beginning of 8-11 contractions $\mathrm{min}^{-1}$ typical for the proximal small intestine [47]. Similarly, ileocecal passage is characterized by change from a $6 \mathrm{~min}^{-1}$ contraction frequency typical for the distal ileum to a $3 \mathrm{~min}^{-1}$ typical for the colon $[48,49]$, and the occurrence of a short fast movement in the lower right quadrant [45].

Contractility patterns in the stomach are analyzed with specialized Motilis software (MTS Tool, Motilis, Lausanne, Switzerland). Mean contraction frequencies in the stomach can be calculated using the rotations of the capsule. Frequency peaks are identified using a convolution of the fast Fourier transforms with the "shape of a peak" described by a Gaussian function is applied. To avoid a Doppler effect whereby 


\section{Use of MTS-1 in research}

\section{— Figure 1 near here -}

\section{Motility Tracking System 1 (MTS-1)}

\section{Technical properties of MTS-1}

MTS-1 consisted of a magnetic capsule, a detection matrix, and dedicated computer software. The capsule measured $\varnothing 6 \times 15 \mathrm{~mm}$, weighed $0.9 \mathrm{~g}$ and contained a permanent cylindrical magnet with a composite density of $1.8 \mathrm{~g} \mathrm{~cm}^{-3}$. The detection matrix consisted of $4 \times 4$ magnetic field sensors separated by $5 \mathrm{~cm}$ and placed in front of the abdomen with the umbilicus as an anatomical landmark. The system was stationary and thus confined the subject under study to stay in a specially designed wooden bed during investigations. Before starting measurements, the matrix was calibrated by off-setting the earth's magnetic field [45].

The use of MTS-1 was identified in 11 studies over an 9-year period (2005-2014) as listed in Table 2. The first clinical study was carried out in 2009 by Hiroz et al., who used the system to track colonic motility in healthy subjects [44]. A validation of pyloric and ileocecal passage was later carried out in 2011 by gluing the magnet to a PillCam (PillCam, Given, Yoqnaem, Israel). This showed that the MTS-1 was a reliable and precise tool to determine pyloric and ileocecal passages. Furthermore, mean contraction frequencies of $2.85( \pm \mathrm{SD} 0.29) \mathrm{min}^{-1}$ in the stomach and $9.90( \pm \mathrm{SD} 0.14) \mathrm{min}^{-1}$ in the small intestine corresponded well to those published with other methods [45].

Worsøe et al. used the MTS-1 to examine potential effects of sacral nerve stimulation on gastric and small intestinal motility in patients with fecal incontinence [50]. The study followed a randomized doubleblind crossover design with patients being assigned to either a week with or without sacral nerve stimulation, followed by an investigation with MTS-1. This led to the finding that turning off sacral nerve stimulation does not have any measured effects on gastric or small intestinal motility patterns. Using a 
similar crossover design in patients with irritable bowel syndrome, Fassov et al. also found no effects of sacral nerve stimulation on gastric emptying and small intestinal transit time [43].

Fynne et al. used MTS-1 to determine orocecal transit time and gastric emptying in patients with neurogenic bowel problems due to spinal cord injury [40]. Importantly, patients had a significantly prolonged upper GI transit time, whatever the spinal cord injury being high or low $(p<0.01)$. Hedsund et al. described GI motility in patients with cystic fibrosis. Contraction frequencies of the stomach and small intestine were normal, but the magnet reached the cecum after 7 hours in only $20 \%$ of patients as compared to $88 \%$ of controls [41]. This can be explained by the distal obstruction syndrome, with stasis in the distal small intestine due to excessively low viscosity of mucus in cystic fibrosis [41].

Karlsen et al. examined patients with moderately severe liver cirrhosis and portal hypertension [38]. Previous studies in these patients had used ROM or lactulose breath tests, the latter which is limited to investigation of orocecal transit times. The use of MTS-1 thus permitted the authors to distinguish between gastric emptying and small intestinal transit time, detecting no difference in gastric emptying, but surprisingly a significantly faster transit through the proximal small intestine in cirrhotic patients than in healthy controls [38]. In another study with MTS-1, Gregersen et al. found similar faster transit times of the small intestine in patients with neuroendocrine tumors [39]. Contrary to these findings, Fynne et al. found patients with systemic sclerosis (SSc) to have a significantly reduced transit time through the proximal small intestine [42].

Clinicians in pediatric gastroenterology face diagnostic difficulties as conventional methods like ROM, scintigraphy, and PillCam ${ }^{\mathrm{TM}}$ involve radiation or the discomfort of swallowing a large pill $(11 \times 26 \mathrm{~mm})$. Therefore, Hedsund et al. trialed the used of the smaller MTS-1 capsule $(6 \times 15 \mathrm{~mm})$ in healthy children aged 7-12. Despite having the inherent restriction of being non-ambulatory, the MTS-1 allowed minimally invasive evaluation of GI motility in children [51].

— Table 2 near here -

\section{D-Transit electromagnetic capsule system (3D-Transit) Technical properties of 3D-Transit}

3D-Transit consists of a wireless electronic capsule for ingestion, an extracorporeal portable detector containing four sensors, and a computer with display and analysis software (Figure 1). The capsule emits a magnetic field modulated at a given low frequency, which allows to filter out the earth's magnetic field and background noise from the surroundings. This feature enables 3D-Transit to be a portable system assessing 
both whole gut and regional transit times and contraction patterns in a fully ambulatory setting in the patients' home environment with only minor restrictions on movements.

Each capsule measures $21.5 \mathrm{~mm} \times 8.3 \mathrm{~mm}$ with a density of $1.6 \mathrm{~g} / \mathrm{cm}^{2}$. Capsules emit a signal with a sampling rate of $10 \mathrm{~Hz}$ or $5 \mathrm{~Hz}$. Recording at $10 \mathrm{~Hz}$ will in theory make it easier to distinguish capsule movement from signal noise. However, all "real" movements are easily shown even at $5 \mathrm{~Hz}$, which is more than enough to calculate movement velocity and movement distances. The lifetime of the battery within the capsule is approximately 48 hours with a sampling rate at $10 \mathrm{~Hz}$. Adjusting the sampling rate to $5 \mathrm{~Hz}$ will double the lifetime of the battery to approximately 96 hours. The increased recording duration at $5 \mathrm{~Hz}$ outweighs the potential lower signal/noise-ratio when studying subjects with suspected long GI transit times, e.g. patients with constipation. Most of the studies using 3D-Transit have recorded with a sampling rate of $5 \mathrm{~Hz}$.

Capsules are synchronized, hence they have no interference with each other. This enables the system to simultaneously record up to three capsules without any interference impediments, even if residing in the same part of the GI tract [28]. By the use of wireless Bluetooth communication, the movements and changes in orientation can be monitored in real time on a computer while also being stored on a memory card within the detector. At the end of the investigation, data are downloaded to the computer. These are then analyzed and used to determine total and regional gastrointestinal transit times and contractile patterns by the use of dedicated software (3D-Transit, Motilis, Lausanne, Switzerland).

The detector has an inbuilt accelerometer for identification of posture changes and body movement artifacts. Likewise, a thoracic belt registers breathing movements. This is particularly convenient during analysis of data from the small intestine where slow wave contractile frequency $\left(9 \mathrm{~min}^{-1}\right)$ is close to breathing frequency. Both are also stored on the memory card and can be monitored in real time.

Due to electromagnetic noise from the surrounding environment possibly affecting the wireless connection between the capsule and the detector, the minimal distance allowable from external electronic devices (e.g. old computers with spinning magnetic hard drives) is approximately $40 \mathrm{~cm}$. There are no restrictions regarding cell phones or tablets as these do not interfere with the connection. To gain reliable data, the detector should be worn continuously throughout the study and only be removed briefly, e.g. when a shower is needed [28].

\section{Data analysis of 3D-Transit}

The 3D-Transit software contains an overview function which depicts the full recording with shifts in contraction frequencies plotted against time (time-frequency plot), thus aiding the analysis (Figure $1 \mathrm{~A}$ ). A recent refinement of 3D-Transit data analysis now enables a much more detailed computation of transit 
times through four segments of the colorectum. This is done by assessing six distinct anatomical landmarks in the colon: (i) start of the colon, (ii) hepatic flexure, (iii) midpoint of the transverse segment, (iv) splenic flexure, (v) end of the descending colon, and (vi) end of the rectum. The 3-dimensional position data can be visualized after down sampling the data from 5-10 datapoints per second using an algorithm that plots data points when the capsule moves $5 \mathrm{~mm}$ within a 3 minutes period (see Figure 2B). Due to the threshold set by the $5 \mathrm{~mm}$ distance, the plotting algorithm enables visualization of time points of slow movement and fast/ movement without showing much non-movement data.

This enables investigators to define transit through six colonic segments: 1) Caecum/ascending colon, 2) transverse colon, 3) descending colon, 4) rectosigmoid colon, 5) total right colon, and 6) total left colon (see Figure 2) [52]. Further, because 3D-Transit allows for highly detailed tracking of the capsules through the entire colon, the system can detect capsule movements that through post-processing can be classified according to movement length, velocity, and direction [53]. The capsule movement through the colon was analyzed using an estimated 'centerline' of capsule progression on to which all capsule position data points were projected [54]. Antegrade and retrograde activity was then analyzed and classified according to thresholds proposed by Hiroz et al. and from analysis of the data distribution of capsule velocity and displacement length in recordings of healthy volunteers [44]. Colonic motility was classified as five specific movement patterns (see Table 3) [53].

No data has been reported on the time-consuming aspect of data analysis. However, from our group's experience, analysis of regional transit times takes approx. 30 minutes while segmental colonic transit times requires approximately 2 hours.

\section{Use of 3D-Transit in research}

Fifteen studies were identified using the 3D-Transit over a six-year period (2014-2020), as listed in Table 5. In healthy volunteer studies, use of the 3D-Transit capsule has provided normative values for regionspecific gastric, small intestinal, and segmental colonic GI transit times [52, 55]. In volunteer and patient studies, the system has provided detailed information on colonic motility not available by any other ambulatory method [53, 56-58]. In clinical studies, the 3D-Transit system has been used to investigate transit times and movement patterns in patient groups including those with severe ulcerative colitis, Parkinson's disease, idiopathic gastroparesis, diabetes mellitus, and carcinoid diarrhea [55, 57, 59-61]. 
Further, the system has shown itself valuable to evaluate the effects of different medications on the GI tract $[56,58,62-64]$.

\section{— Table 5 near here -}

\section{Normative values}

Based on recordings from 132 healthy subjects, Sutter et al. established normative data for gastric motility assessed with 3D-Transit [55]. The median gastric emptying time (GET) was 2.7 hours, reproducing previous results found with WMC (3.2 hours) [65]. Gastric contractions were detectable for a median of $92 \%$ of the time. Their median frequency was $3.1 \mathrm{~min}^{-1}$ which corresponds very well to those described by electrogastrography and antroduodenal manometry [66]. A representative examination of capsule progression through the stomach is shown in Figure 3.

\section{— Figure 3 near here -}

Haase et al. assessed GI motility during sleep monitored by polysomnography and found that the amplitude of gastric contractions decreased with the depth of sleep (light sleep versus deep sleep). Moreover, basal colonic activity decreased significantly across sleep stages and was significantly less during deep sleep and light sleep compared with wake periods [58].

In 2019, Nandhra et al. used 3D-Transit to establish normative values for total and region-specific GI and segmental colonic transit times [52]. Recordings were pooled from nine previously published clinical studies carried out between 2012 and 2017, totaling 111 healthy adults [28, 53, 59-61, 63, 64, 67, 68]. They found median transit times as presented in Table 4.

These correlate well with those found by Wang et al. using WMC [65]. Nandhra et al. also analyzed for influence of gender, age, and BMI. Increasing age was significantly associated with longer colonic transit time and whole gut transit time while increasing BMI was associated with longer whole gut transit time [52]. Female gender was associated with longer transverse and descending colonic transit time but shorter rectosigmoid colonic transit time. The authors found good to excellent inter- and intra-rater reliability of the segmental colonic transit times [52].

Whole gut and colorectal transit times were found to cluster in groups separated by approximately 24 hours. Notably, most capsules (38\%) were expelled between 06:00 and 08:00, regardless of the group. Furthermore, capsules ingested in the evening trended towards a longer colorectal transit time than capsules ingested in the morning $[28,53]$. This reflects that whole gut transit time (and colonic transit time) 
is dependent on morning defecation habits as commonly seen in healthy individuals [65]. It also supports the knowledge of the non-continuous nature of GI transit [52]. Additionally, Kalsi et al. demonstrated that inter-rater and intra-rater reliability was high to excellent when performed by experienced raters whereas inexperienced raters had low to fair reliability [69]. This emphasizes that differences in transit times are caused by biological variations rather than methodological issues and that raters must be adequately trained.

In the recent years, there has been an improvement in the 3D-Transit software algorithm, based on the analytical software for the stationary MTS-1. Besides detailed segmental colonic transit times, the software now enables detailed analyses of colonic movement patterns [44, 53]. Hence, Mark et al. reanalyzed recordings on healthy subjects from three previous studies and published their results in a comprehensive series of papers on colonic motility $[28,44,53,59,64]$. They found that capsule movement velocities varied greatly, ranging from $180 \mathrm{~cm} \mathrm{~min}^{-1}$ (antegrade displacement) to $-180 \mathrm{~cm} \mathrm{~min}^{-1}$ (retrograde displacement), and peaked in three groups: fast antegrade $\left(50 \mathrm{~cm} \mathrm{~min}^{-1}\right)$, slow antegrade $\left(0.5 \mathrm{~cm} \mathrm{~min}{ }^{-1}\right)$, and slow retrograde $\left(-0.5 \mathrm{~cm} \mathrm{~min}^{-1}\right)$. Moreover, Interestingly, recordings with comparable colorectal transit times could represent highly variable types of capsule progression through the various segments (Figure 4) [53].

A recent cine-MRI study also reported quantitative data of antegrade and retrograde contraction velocities, although they observed more retrograde activity using their novel imaging approach [70].

\section{$3 D$-Transit studies in patients}

Gregersen et al. were the first to use 3D-Transit in a group of patients suffering from bowel dysmotility [59]. In patients with carcinoid diarrhea due to neuroendocrine tumors, the authors found the median whole gut transit time to be about $50 \%$ that of healthy subjects while small intestinal transit time was $86.4 \%$ of normal and median colonic transit time only $29 \%$ of normal. Corresponding to this, patients with carcinoid diarrhea had significantly more long fast antegrade colonic movements and their antegrade colonic movements covered twice the distance observed among healthy subjects $[53,59]$.

In patients with diarrhea caused by severe ulcerative colitis, Haase et al. surprisingly found a prolonged median whole gut transit time of 44.5 hours compared to 27.6 hours in healthy subjects [60]. This was mainly due to extended transit through the right side of the colon. Likewise, there was a strong trend towards a prolonged transit in the small intestine. The conclusion drawn from this study was that severe inflammation of the distal colon inhibits motility in more proximal segments of the gut [60]. 


\section{D-Transit in pharmacological studies}

A common side-effect of opioid use is constipation. Four studies have assessed gastrointestinal aspects of opioid treatment in healthy volunteers using 3D-Transit [56, 62-64].

Poulsen et al. compared the impact of opioids on regional GI transit in a double-blind, crossover trial with healthy subjects assigned to either oxycodone or placebo for five days. They found significantly prolonged cecum-ascending, rectosigmoid, and total colonic transit timés [64]. Mark et al. subsequently found a significant reduction in long fast antegrade movements and an increase in slow antegrade movements in the oxycodone group. Finally, the oxycodone group had a significantly decreased capsule movement velocity compared with the placebo group [56].

Olesen et al. examined the alleviating effects of the peripherally-acting opioid antagonist naloxegol on oxycodone-induced constipation [62]. Naloxegol significantly reduced colonic transit time by $23 \%$ compared to placebo. Of segmental colonic transit times, only rectosigmoid colonic transit time was significantly reduced compared to placebo [62]. Like the study by Poulsen et al., data were further processed, and it was found that naloxegol decreased the number of slow antegrade movements. Fast antegrade movements were also of a longer distance in the naloxegol group than in the placebo group [56].

Mark et al. suggests that increased transit times during opioid treatment can be attributed to a decrease in long fast movements, despite an increase in the number of slow antegrade movements [56]

Finally, Poulsen et al. compared the effects of slow-release naloxone and the osmotically acting laxative macrogol 3350 (both administered with slow-release oxycodone to induce bowel dysfunction) in a randomized, double-blind, crossover trial. Both drugs seem to have comparable effects on GI transit as no difference was found in regional GI transit times nor segmental colonic transit times [63].

The 3D-Transit motility measurements have been shown to detect motility disturbances induced by pharmacological interventions, however the clinical value of such information of motility patterns may be difficult to understand as of now. Additional studies in relevant patient groups may find interesting 
associations between clinical parameters and the number, distance or velocity of different motility patterns.

\section{Challenges and limitations of 3D-Transit}

Assessing gastrointestinal motility with electromagnetic capsule-based methods, such as the 3D-Transit system, is challenging due to data loss, manual analysis, lack of availability, and the non-direct measurement of $\mathrm{Gl}$ contractions. Data loss has been reported in between $13.3 \%$ and $21 \%$ of recordings [52, 53], mainly due to loss of transmission signal and poor recording quality. This issue may be circumvented to an extent if subjects under study are urged to reduce their physical activity during recording, though true, inactivity may itself impact motility of the gut.

Manual analysis of the 3D-Transit recordings is a limitation, especially if performed by inexperienced investigators [69]. However, when performed by adequately or highly trained investigators the system has shown excellent intra-rater and inter-rater reliability [52]. Furthermore, manual extraction of data from each recording is heavily time-consuming. Both drawbacks inform the need for automatization of the system to ensure consistency and to improve the speed of processing.

Another obvious limitation to the 3D-Transit system is its lack of approval from the US Food and Drug Administration and the European Union through CE-marking. 3D-Transit is thus currently restricted to use in research facilities and is not commercially available.

Finally, a limitation inherent to all telemetric capsule systems, is the lack of information at segments where the capsule is not present, which means that assessment of contractions is only carried out at the exact location of the capsule(s) and important information may be missed. Additionally, the 3D-Transit system does not directly measure the pressure amplitude of contractions. Both of these limitations are overcome by HRM, where changes in pressure in each centimeter of the colon are directly measured, though clearly HRM is a much more invasive method [71]. A validation study comparing 3D-Transit and HRM must be done to directly associate motor patterns recorded with the 3D-Transit system.

\section{Future perspectives}

Electromagnetic tracking of GI motility shows great promise as a future clinical diagnostic tool. 3D-Transit is the only available tool to provide simultaneous assessment of GI transit and movement patterns, and thus aid in characterizing and diagnosing GI diseases and the effects of treatment. Another potential advantage of capsule-based magnetic tracking is its ability to potentially determine the velocity at which medication 
reach a specific segment of the Gl tract, although further studies are needed to compare size and composition of the pills and the 3D-Transit capsule.

3D-Transit also holds promising potentials for pediatric gastroenterology as a minimally invasive procedure. As described, a previous study has applied the MTS-1 system in healthy children, but studies validating the use of 3D-Transit in the pediatric population are warranted.

\section{Conclusions}

3D-Transit shares similarities with the wireless motility capsule (WMC) as they are both capsule-based, ambulatory, and minimally invasive. Both methods enable assessment of regional transit times throughout the gut, which is essential as most motility disorders affect more than a single region of the GI tract. The 3D-Transit system, however, differs in two essential ways. Its spatiotemporal resolution allows assessment of segmental colonic transit times. Moreover, the 3D-Transit system permits an analysis of gastric and colonic movements with a degree of detail unrivalled by other ambulatory methods. Recently, robust normative data have been published. The system still holds notable limitations. It is neither CE approved nor generally commercially available. Data analysis need further improvement and automatization before the system can be widely adopted in clinical practice. 


\section{Legends for illustrations}

\section{Figure 1: Motilis 3D-Transit system}

The 3D-Transit system. A) Overview function: The frequency of contractions helps determine pyloric and ileocecal passages by changes in gastrointestinal contraction frequency. Pyloric passage is found around the increase from 3 to 9-12 contractions $\mathrm{min}^{-1}$, and ileocecal passage is found around the decline from approximately 6 to 3 contractions $\mathrm{min}^{-1}$. B) 3D-Transit recording of a single capsule as seen in dedicated 3DTransit software. Pyloric passage of electromagnetic capsule (yellow line). The position $(x, y, z)$ and orientation $(\theta, \varphi)$ of the capsule are displayed. The 2D-plot $(x, y)$ in the upper left corner displays movement through the duodenal arch and is monitored and verified with respect to changes in trajectory and loss of three contractions $\mathrm{min}^{-1}$ (arrows) characteristic of gastric motility.
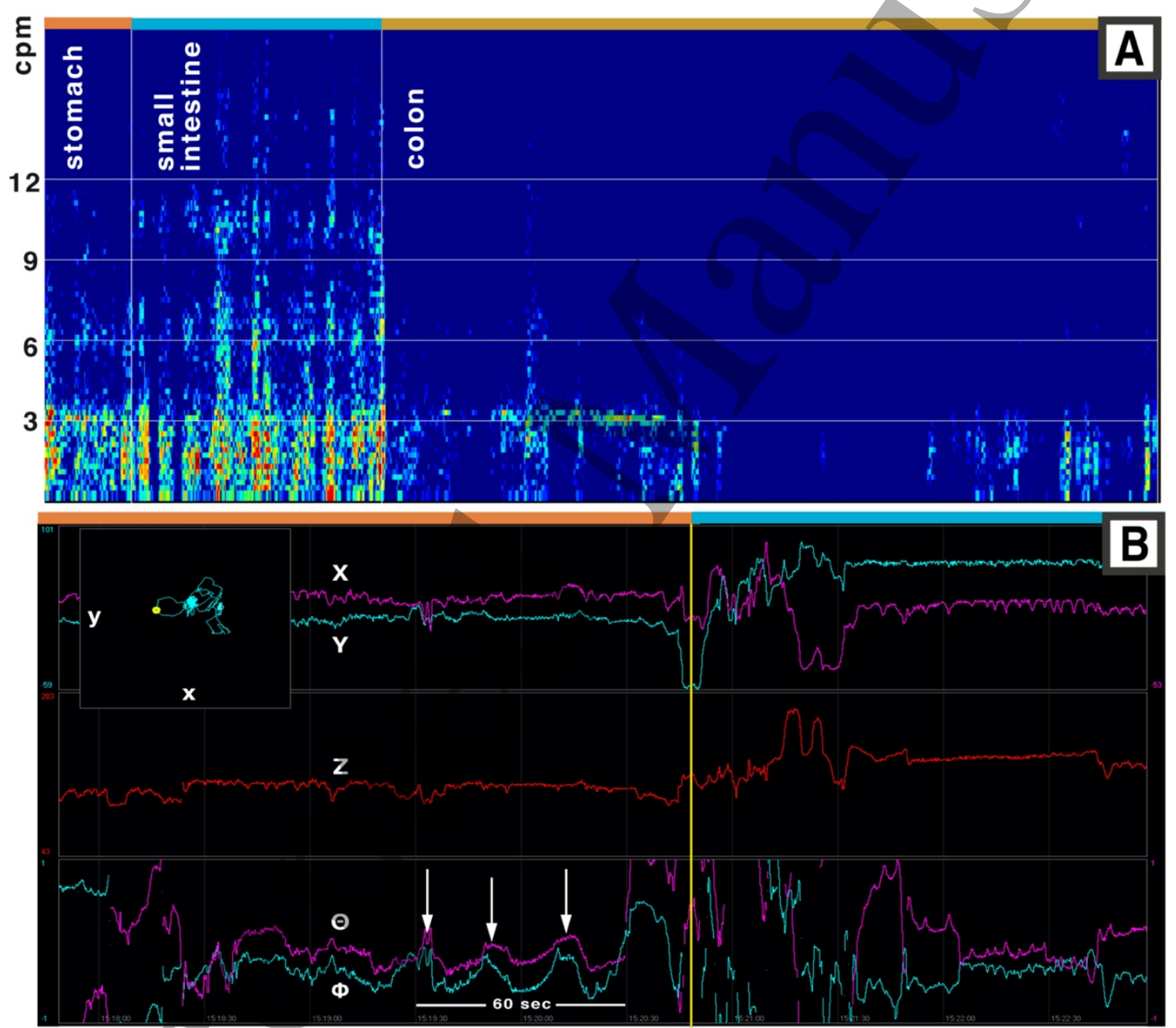


\section{Figure 2: Colonic anatomy and landmarks.}

Graphical overview of colonic anatomy and the colonic progression of a 3D-transit capsule. A) Colonic anatomy with segments and six distinct anatomical landmarks marked according to the 3D-Transit analysis: (I) lleo-cecal passage, (II) hepatic flexure, (III) midpoint of the transverse colon, (IV) splenic flexure, (V) end of the descending colon, and (VI) distal end of the rectum. B) Graphical presentation of processed colonic data from a healthy male. Arabic numerals specify location of the capsule in relation to hours spent in the colon.

A

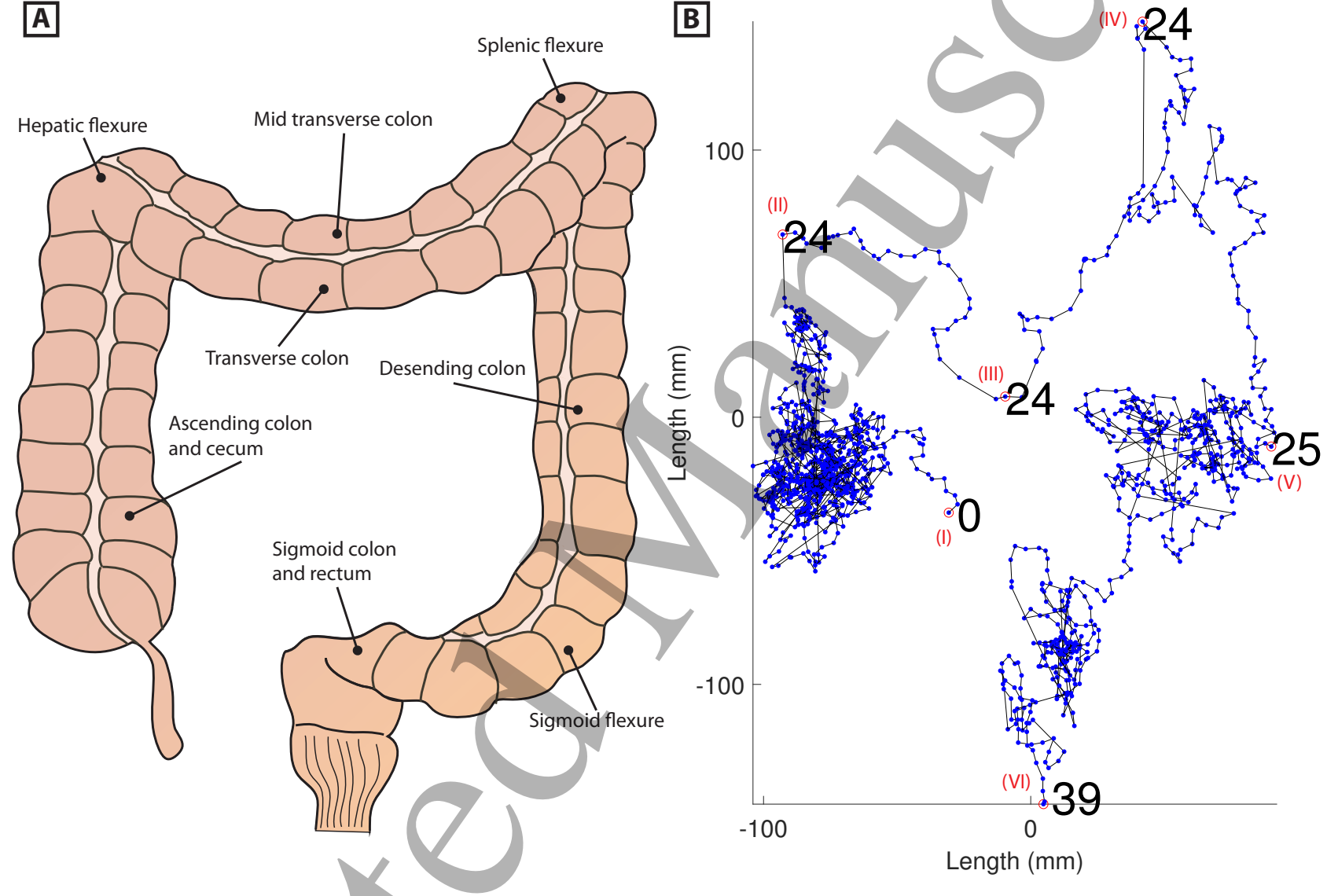




\section{Figure 3: Gastric emptying time}

3D-Transit recording from a healthy subject displayed in two projections. The capsule mostly resided in the antrum of the stomach. Position of the capsule at 20-min intervals is marked with Arabic numerals, connected by the dashed blue line.

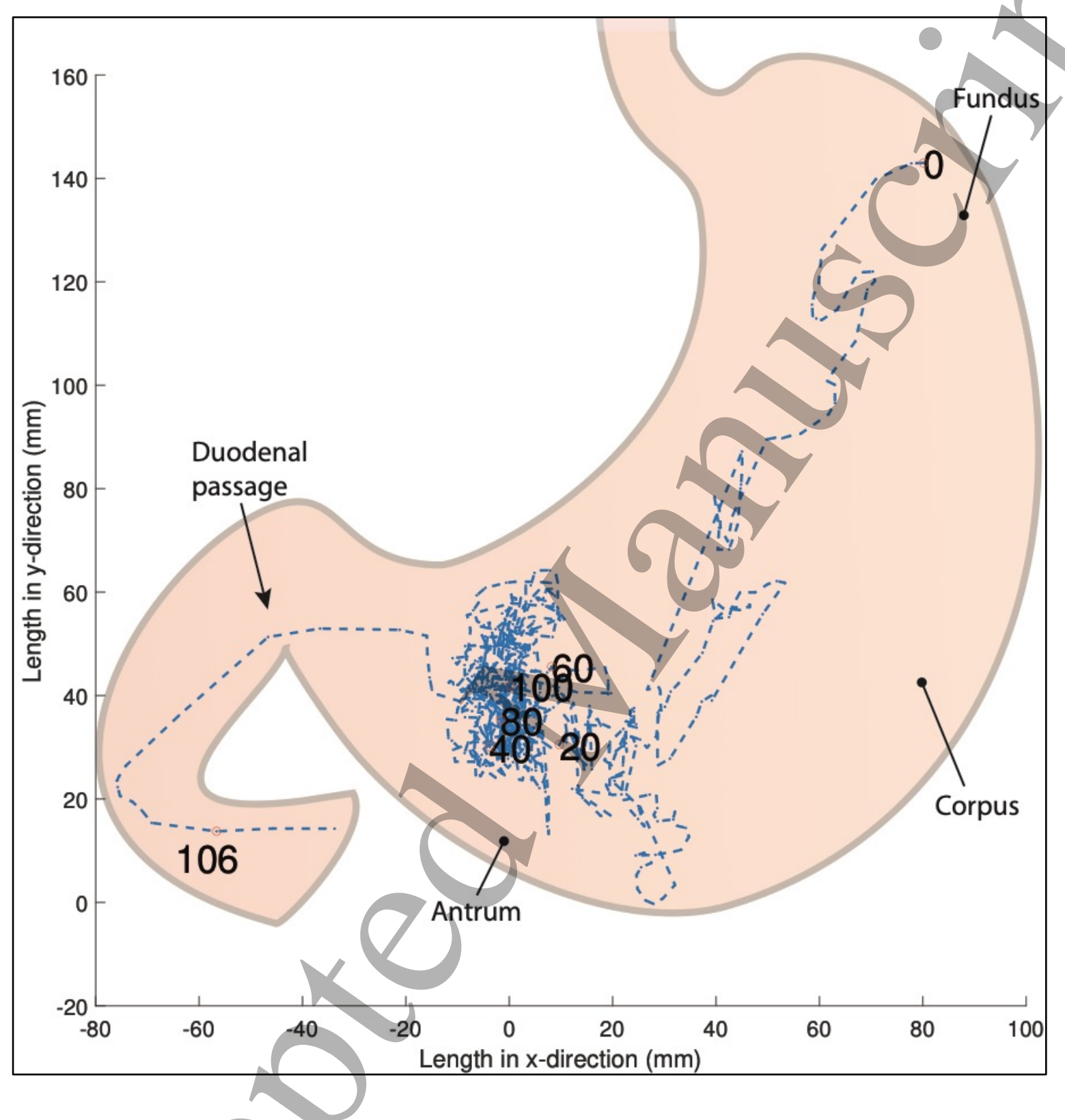




\section{Figure 4: Progression through the colon}

Three types of colonic progression patterns recorded with the 3D-Transit system. Anatomical position in colon is represented by the distance in $\mathrm{cm}$ from cecum to the rectum ( $Y$-axis) plotted against time in hours spent in the colon ( $X$-axis). Analysis of progression patterns are divided into fast progression (red), slow progression (blue), and very slow/no progression (black). A) Typical example of recording in a healthy young male with a normal progression pattern and a total colonic transit of just below 20 hours. B) Representative sample of recording in a patient with diarrhea demonstrating a fast progression pattern and a total colonic transit time below 6 hours. Two long fast antegrade movements accounts for approx. 40-50 $\mathrm{cm}$, respectively. C) Recording from a representative male with opioid-induced constipation demonstrating a slow progression pattern during the first 90 hours and a long fast antegrade movement for the last $50 \mathrm{~cm}$. Total colonic transit time was approx. 70 hours.
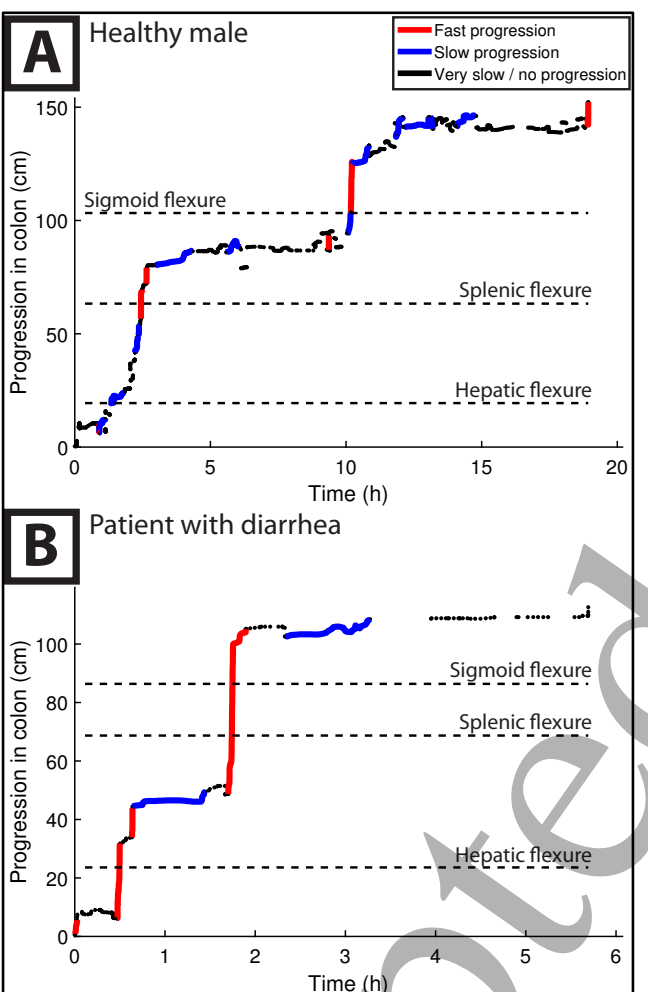

C Male with opioid-induced constipation

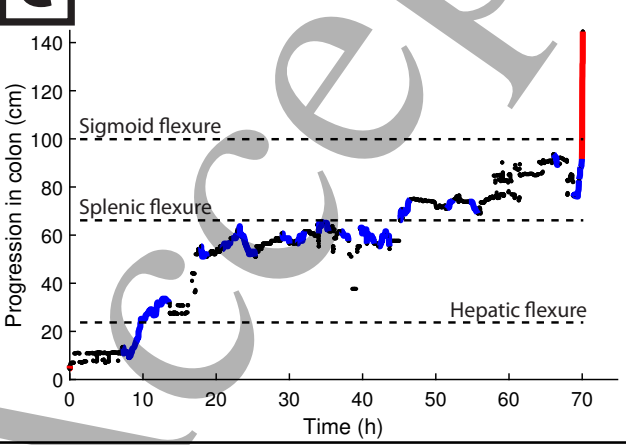




\section{Table 1: Established and emerging methods to assess gastrointestinal motility}

Advantages and disadvantages of established and emerging methods to assess gastrointestinal motility.

\section{Table 1: Established and emerging methods to assess gastrointestinal motility}

\begin{tabular}{|c|c|c|c|c|}
\hline & Method & $\begin{array}{l}\text { Measurement in the } \\
\text { gastrointestinal tract }\end{array}$ & Advantages & Disadvantages \\
\hline \multirow{6}{*}{ 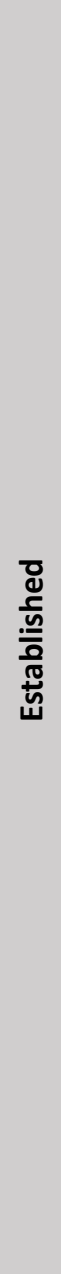 } & $\begin{array}{l}\text { Standard radio-opaque } \\
\text { markers (ROM) }\end{array}$ & $\begin{array}{l}\text { Whole gut transit times } \\
\text { Segmental colonic transit } \\
\text { times (derived) }\end{array}$ & $\begin{array}{l}\text { Minimally invasive } \\
\text { Inexpensive } \\
\text { Poorly standardized } \\
\text { Easy interpretation of data }\end{array}$ & $\begin{array}{l}\text { No direct information on colonic } \\
\text { transit time } \\
\text { Intake of markers depends on } \\
\text { the compliance of the patient }\end{array}$ \\
\hline & Scintigraphy & $\begin{array}{l}\text { Gastric emptying time } \\
\text { Small intestinal transit } \\
\text { time } \\
\text { Colonic transit time }\end{array}$ & $\begin{array}{l}\text { Minimally invasive } \\
\text { High reliability }\end{array}$ & $\begin{array}{l}\text { Subject irradiation } \\
\text { Time consuming } \\
\text { Difficult data analysis } \\
\text { Expensive }\end{array}$ \\
\hline & $\begin{array}{l}\text { Antroduodenal } \\
\text { manometry }\end{array}$ & $\begin{array}{l}\text { Motility patterns in } \\
\text { stomach and duodenum }\end{array}$ & $\begin{array}{l}\text { High reliability } \\
\text { Radiation free }\end{array}$ & $\begin{array}{l}\text { Invasive } \\
\text { Lacks standardization } \\
\text { Time consuming } \\
\text { Limited to specialized centers }\end{array}$ \\
\hline & $\begin{array}{l}\text { High-resolution } \\
\text { manometry (HRM) }\end{array}$ & $\begin{array}{l}\text { Motility patterns in } \\
\text { esophagus, stomach, } \\
\text { duodenum, and colon }\end{array}$ & $\begin{array}{l}\text { Radiation free } \\
\text { High resolution assessment } \\
\text { of motility }\end{array}$ & $\begin{array}{l}\text { Invasive } \\
\text { Expensive } \\
\text { Difficult data analysis } \\
\text { Bowel preparation (colon) }\end{array}$ \\
\hline & $\begin{array}{l}\text { Wireless motility } \\
\text { capsule (SmartPill) }\end{array}$ & $\begin{array}{l}\text { Whole gut and regional } \\
\text { transit times }\end{array}$ & $\begin{array}{l}\text { Minimally invasive } \\
\text { High standardization } \\
\text { Easy to perform } \\
\text { Robust normative data } \\
\text { Radiation free } \\
\text { Ambulatory }\end{array}$ & $\begin{array}{l}\text { No information on segmental } \\
\text { colonic transit times }\end{array}$ \\
\hline & Hydrogen breath test & Orocecal transit time & $\begin{array}{l}\text { Non-invasive } \\
\text { High standardization } \\
\text { Inexpensive } \\
\text { Radiation free }\end{array}$ & $\begin{array}{l}\text { Confounding pitfalls } \\
\text { Does not distinguish between } \\
\text { gastric emptying and small } \\
\text { intestinal transit }\end{array}$ \\
\hline \multirow{3}{*}{ 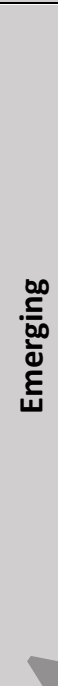 } & $\begin{array}{l}\text { MRI motility } \\
\text { assessments }\end{array}$ & $\begin{array}{l}\text { Whole gut and regional } \\
\text { transit times } \\
\text { Colonic and small } \\
\text { intestinal motility patterns }\end{array}$ & $\begin{array}{l}\text { Non-invasive } \\
\text { No radiation exposure }\end{array}$ & $\begin{array}{l}\text { No standardization } \\
\text { Expensive } \\
\text { Difficult data analysis }\end{array}$ \\
\hline & $\begin{array}{l}\text { Endoluminal image } \\
\text { analysis }\end{array}$ & $\begin{array}{l}\text { Motility patterns in the } \\
\text { small bowel }\end{array}$ & $\begin{array}{l}\text { Non-invasive } \\
\text { Operator-independent High } \\
\text { sensitivity }\end{array}$ & $\begin{array}{l}\text { No information on GI transit } \\
\text { times } \\
\text { Restricted to research } \\
\text { Requires further validation }\end{array}$ \\
\hline & 3D-Transit sy & $\begin{array}{l}\text { Whole gut and regional } \\
\text { transit times } \\
\text { Segmental colonic transit } \\
\text { times } \\
\text { Motility patterns in the } \\
\text { stomach and colon }\end{array}$ & $\begin{array}{l}\text { Minimally invasive } \\
\text { Radiation free } \\
\text { Ambulatory } \\
\text { Provides both motility and } \\
\text { transit data under near } \\
\text { normal physiological } \\
\text { conditions } \\
\text { Robust normative data }\end{array}$ & $\begin{array}{l}\text { No standardization } \\
\text { Difficult data analysis } \\
\text { Not commercially available }\end{array}$ \\
\hline
\end{tabular}




\section{Table 2: Previous studies with MTS-1}

List of studies using the motility tracking system (MTS-1) and their main findings. Abbreviations: Gl, gastrointestinal; GE, gastric emptying; SITT, small intestinal transit time; CTT, colonic transit time.

\section{Table 2: Previous studies with MTS-1}

\begin{tabular}{|c|c|c|}
\hline Author (year) & Subjects investigated ( $n$ ) & Main find \\
\hline Stathopoulos et al. (2005) [27] & Healthy subjects $(n=10)$ & MTS-1 proved feasible in healthy subjects \\
\hline Hiroz et al. (2009) [44] & Healthy subjects $(n=20)$ & $\begin{array}{l}\text { MTS-1 allowed detailed tracking of capsule } \\
\text { movements within the colon }\end{array}$ \\
\hline Worsøe et al. (2011) [45] & Healthy subjects $(n=8)$ & MTS-1 was validated against PillCam. \\
\hline Worsøe et al. (2012) [50] & $\begin{array}{l}\text { Patients with fecal incontinence } \\
(n=8)\end{array}$ & $\begin{array}{l}\text { No effects of sacral nerve stimulation on GE and } \\
\text { SITT }\end{array}$ \\
\hline Fassov et al. (2014) [43] & $\begin{array}{l}\text { Patients with irritable bowel } \\
\text { syndrome }(n=20)\end{array}$ & $\begin{array}{l}\text { No effects of sacral nerve stimulation on GE or } \\
\text { SITT }\end{array}$ \\
\hline Fynne et al. (2012) [40] & $\begin{array}{l}\text { Patients with neurogenic bowel } \\
\text { problems due to spinal cord injury } \\
\text { ( } n=19 \text { ) } \\
\text { Healthy controls ( } n=15 \text { ) }\end{array}$ & $\begin{array}{l}\text { Patients with spinal cord injury had prolonged GE } \\
\text { Basic contraction frequencies of the stomach and } \\
\text { small intestine were unaffected by spinal cord } \\
\text { injury }\end{array}$ \\
\hline Hedsund et al. (2012) [41] & $\begin{array}{l}\text { Patients with pancreatic } \\
\text { insufficiency caused by cystic } \\
\text { fibrosis }(n=10) \\
\text { Healthy controls }(n=16)\end{array}$ & $\begin{array}{l}\text { Patients with cystic fibrosis had distal obstruction } \\
\text { syndrome in the small intestine }\end{array}$ \\
\hline Karlsen et al. (2012) [38] & $\begin{array}{l}\text { Patients with bowel problems due } \\
\text { to liver cirrhosis and portal } \\
\text { hypertension }(n=15) \\
\text { Healthy controls }(n=18)\end{array}$ & $\begin{array}{l}\text { Patients with moderate cirrhosis had faster than } \\
\text { normal transit through the proximal small } \\
\text { intestine }\end{array}$ \\
\hline Fynne et al. (2011) [42] & $\begin{array}{l}\text { Patients with systemic sclerosis }(n= \\
15)\end{array}$ & $\begin{array}{l}\text { Patients with systemic sclerosis had prolonged } \\
\text { SITT }\end{array}$ \\
\hline Gregersen et al. (2011) [39] & $\begin{array}{l}\text { Patients with carcinoid syndrome } \\
\text { due to neuroendocrine tumors } \\
(n=12) \\
\text { Healthy controls }(n=12)\end{array}$ & $\begin{array}{l}\text { Patients with carcinoid syndrome had faster than } \\
\text { normal SITT and WGTT }\end{array}$ \\
\hline Hedsund et al. (2013) [51] & Healthy children $(n=21)$ & $\begin{array}{l}\text { Regional contraction frequencies and transit } \\
\text { times in healthy children were determined and } \\
\text { corresponded well to those previously observed } \\
\text { in adults }\end{array}$ \\
\hline
\end{tabular}


Table 3: Colonic motility movement patterns

Colonic motility classified from the five predominant types of movement patterns [53].

\begin{tabular}{|l|l|l|}
\hline \multicolumn{2}{|c|}{ Table 3: Colonic motility movement patterns } \\
\hline \multicolumn{1}{|c|}{ Colonic movement } & \multicolumn{1}{|c|}{ Distance } & \multicolumn{1}{c|}{ Velocity } \\
\hline Long fast antegrade & $>10 \mathrm{~cm}$ & $>10 \mathrm{~cm} \mathrm{~min}^{-1}$ \\
\hline Fast antegrade & $4-10 \mathrm{~cm}$ & $>4 \mathrm{~cm} \mathrm{~min}^{-1}$ \\
\hline Slow antegrade & $>4 \mathrm{~cm}$ & $\begin{array}{l}<4 \mathrm{~cm} \mathrm{~min}^{-1} \\
>4 \mathrm{~cm} \mathrm{~h}^{-1}\end{array}$ \\
\hline Slow retrograde & $<4 \mathrm{~cm}$ & $\begin{array}{l}<4 \mathrm{~cm} \mathrm{~min}^{-1} \\
>4 \mathrm{~cm} \mathrm{~h}^{-1}\end{array}$ \\
\hline Fast retrograde & $<4 \mathrm{~cm}$ & $>4 \mathrm{~cm} \mathrm{~min}^{-1}$ \\
\hline
\end{tabular}

Table 4: Normative values for gastrointestinal transit times assessed with 3D-

\section{Transit}

Normative values for total and region-specific gastrointestinal transit times, based on 111 healthy adults [52].

\begin{tabular}{|l|l|l|}
\hline \multicolumn{2}{|l|}{ Table 4: Normative values for gastrointestinal transit times assessed } \\
with 3D-Transit & $\begin{array}{r}\text { Transit time } \\
\text { (hours:min) }\end{array}$ & \multicolumn{1}{c|}{$\begin{array}{c}95 \% \mathrm{Cl} \\
\text { (hours:min) }\end{array}$} \\
\hline Gastrointestinal region & $2: 41$ & $2: 29-3: 06$ \\
\hline Gastric emptying time & $4: 47$ & $4: 20-5: 06$ \\
\hline Small intestinal transit time & $21: 06$ & $18: 39-23: 54$ \\
\hline Colonic transit time & $28: 52$ & $25: 37-30: 48$ \\
\hline Whole gut transit time & & \\
\hline
\end{tabular}




\section{Table 5: Previous studies with 3D-Transit}

List of studies using the Motilis 3D-Transit system and their main findings. Abbreviations: Gl; gastrointestinal, GE, gastric emptying; WGTT, whole gut transit time, SITT, small intestinal transit time; CTT, colonic transit time; CATT, caecum ascending transit time; DM-1, type 1 diabetes mellitus. 
1

Table 5: Studies using the 3D-Transit system

\begin{tabular}{|c|c|c|c|}
\hline & Author (year) & Subjects investigated (n) & Main findings \\
\hline \multirow{7}{*}{ 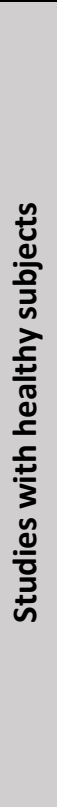 } & $\begin{array}{l}\text { Haase et al. (2014) } \\
\text { [28] }\end{array}$ & Healthy subjects $(n=20)$ & $\begin{array}{l}\text { 3D-Transit proved feasible in healthy subjects. } \\
\text { Good correlation of WGTT assessment between } \\
\text { 3D-Transit and ROM }\end{array}$ \\
\hline & Mark et al. (2017) [67] & $\begin{array}{l}\text { Healthy subjects } \\
-\quad \text { 3D-Transit + MRI }(n=25) \\
-\quad 3 D-\text { Transit x } 2(n=21)\end{array}$ & $\begin{array}{l}\text { 3D-Transit proved accurate determination of } \\
\text { colorectal length compared with MRI and between } \\
\text { days }\end{array}$ \\
\hline & Kalsi et al. (2018) [69] & Healthy subjects $(n=36)$ & $\begin{array}{l}\text { Rating of 3D-Transit recordings require adequate } \\
\text { training }\end{array}$ \\
\hline & Nandhra et al. (2019) [52] & Healthy subjects $(n=111)$ & $\begin{array}{l}\text { 3D-transit used to establish normative reference } \\
\text { values for region specific GITT and CTT }\end{array}$ \\
\hline & Sutter et al. (2020) [55] & Healthy subjects $(n=132)$ & $\begin{array}{l}\text { 3D-transit used to establish normative reference } \\
\text { values for gastric motility }\end{array}$ \\
\hline & Mark et al. (2019) [53] & Healthy subjects $(n=34)$ & $\begin{array}{l}\text { 3D-transit used to establish normative reference } \\
\text { values for segmental colonic motility established }\end{array}$ \\
\hline & Haase et al. (2015) [58] & Healthy subjects $(n=9)$ & $\begin{array}{l}\text { 3D-Transit combined with polysomnography allows } \\
\text { investigation of associations between sleep } \\
\text { patterns and GI motility }\end{array}$ \\
\hline \multirow{4}{*}{ 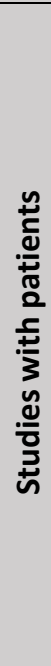 } & $\begin{array}{l}\text { Gregersen et al. (2015) } \\
\text { [59] }\end{array}$ & $\begin{array}{l}\text { Patients with carcinoid diarrhea } \\
\text { due to neuroendocrine tumors } \\
\text { ( } n=7) \\
\text { Healthy controls }(n=15)\end{array}$ & $\begin{array}{l}\text { Patients with carcinoid diarrhea had increased } \\
\text { WGTT in different segments. } \\
\text { Patients had increased frequency of pansegmental } \\
\text { colonic movements }\end{array}$ \\
\hline & $\begin{array}{l}\text { Haase et al. (2016) } \\
{[60]}\end{array}$ & $\begin{array}{l}\text { Patients with severe ulcerative } \\
\text { colitis }(n=20) \\
\text { Healthy controls }(n=20)\end{array}$ & $\begin{array}{l}\text { Patients with severe ulcerative colitis had } \\
\text { prolonged WGTT, significantly in the proximal } \\
\text { colon }\end{array}$ \\
\hline & Knudsen et al. (2017) [61] & $\begin{array}{l}\text { Patients with Parkinson's disease } \\
(n=22) \\
\text { Healthy controls }(n=15)\end{array}$ & $\begin{array}{l}\text { Patients with Parkinson's disease had significantly } \\
\text { increased SITT and CATT }\end{array}$ \\
\hline & $\begin{array}{l}\text { Klinge et al. (2020) } \\
\text { [57] }\end{array}$ & $\begin{array}{l}\text { Patients with type-1 diabetes } \\
\text { mellitus (DM-1) }(n=18) \\
\text { Healthy controls }(n=20)\end{array}$ & $\begin{array}{l}\text { Patients with DM-1 had increased GE, CTT and } \\
\text { WGTT } \\
\text { Patients with DM-1 had an increased number of } \\
\text { retrograde movements }\end{array}$ \\
\hline \multirow{4}{*}{ 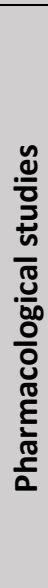 } & Poulsen et al. (2016) [64] & ny subjects $(n=25)$ & $\begin{array}{l}\text { 3D-Transit proved feasible in a pharmacological } \\
\text { study } \\
\text { Oxycodone treatment increases GI transit time in } \\
\text { different Gl segments }\end{array}$ \\
\hline & Olesen et al. (2019) [62 & Healthy subjects $(n=24)$ & $\begin{array}{l}\text { Oxycodone-induced increase in WGTT and CTT is } \\
\text { reversed by naloxegol }\end{array}$ \\
\hline & Poulsen et al. (2018) & Healthy subjects $(n=20)$ & $\begin{array}{l}\text { Oxycodone-induced increase of GI transit time is } \\
\text { equally alleviated by naloxone and macrogol } 3350\end{array}$ \\
\hline & Mark et al. (2019) [56] & $\begin{array}{l}\text { Healthy subjects }(n=59) \text { combined } \\
\text { from [62] and [64] }\end{array}$ & $\begin{array}{l}\text { Increased GI transit time during opioid treatment is } \\
\text { caused by a decrease in long fast movements } \\
\text { rather than uncoordinated peristalsis }\end{array}$ \\
\hline
\end{tabular}




\section{REFERENCES}

1. Sanders, K.M., S.D. Koh, and S.M. Ward, Interstitial cells of cajal as pacemakers in the gastrointestinal tract. Annu Rev Physiol, 2006. 68: p. 307-43.

2. Camilleri, M., et al., Gastroparesis. Nat Rev Dis Primers, 2018. 4(1): p. 41.

3. Camilleri, M., et al., Chronic constipation. Nat Rev Dis Primers, 2017. 3: p. 17095.

4. $\quad$ Enck, P., et al., Irritable bowel syndrome. Nat Rev Dis Primers, 2016. 2: p. 16014.

5. Sanchez, M.I.P. and P. Bercik, Epidemiology and burden of chronic constipation. Canadian journal of gastroenterology = Journal canadien de gastroenterologie, 2011. 25 Suppl B(Suppl B): p. 11B-15B.

6. Card, T., C. Canavan, and J. West, The epidemiology of irritable bowel syndrome. Clinical Epidemiology, 2014: p. 71.

7. Locke, G.R., 3rd, et al., Overlap of gastrointestinal symptom complexes in a US community. Neurogastroenterology and motility : the official journal of the European Gastrointestinal Motility Society, 2005. 17(1): p. 29-34.

8. Dinning, P.G., et al., Colonic motor abnormalities in slow transit constipation defined by high resolution, fibre-optic manometry. Neurogastroenterol Motil, 2015. 27(3): p. 379-88.

9. Grønlund, D., et al., Established and emerging methods for assessment of small and large intestinal motility. Neurogastroenterology \& Motility, 2017. 29(7): p. e13008.

10. Yin, J. and J.D. Chen, Electrogastrography: methodology, validation and applications. J Neurogastroenterol Motil, 2013. 19(1): p. 5-17.

11. O'Grady, G., et al., Methods for High-Resolution Electrical Mapping in the Gastrointestinal Tract. IEEE Rev Biomed Eng, 2019. 12: p. 287-302.

12. Parkman, H.P., Assessment of Gastric Emptying and Small-Bowel Motility: Scintigraphy, Breath Tests, Manometry, and SmartPill. Gastrointestinal Endoscopy Clinics of North America, 2009. 19(1): p. 49-55.

13. Bredenoord, A.J., et al., Chicago classification criteria of esophageal motility disorders defined in high resolution esophageal pressure topography. Neurogastroenterology and motility : the official journal of the European Gastrointestinal Motility Society, 2012. 24 Suppl 1(Suppl 1): p. 57-65.

14. Krevsky, B., et al., Colonic transit scintigraphy. A physiologic approach to the quantitative measurement of colonic transit in humans. Gastroenterology, 1986. 91(5): p. 1102-1112.

15. Metcalf, A.M., et al., Simplified assessment of segmental colonic transit. Gastroenterology, 1987. 92(1): p. 40-47.

16. Rao, S.S.C., et al., Evaluation of gastrointestinal transit in clinical practice: position paper of the American and European Neurogastroenterology and Motility Societies. Neurogastroenterology \& Motility, 2011. 23(1): p. 8-23.

17. Bonapace, E.S., et al., Whole gut transit scintigraphy in the clinical evaluation of patients with upper and lower gastrointestinal symptoms. The American journal of gastroenterology, 2000. 95(10): $p$. 2838-2847.

18. Keller, J., et al., Expert consensus document: Advances in the diagnosis and classification of gastric and intestinal motility disorders. Nature reviews. Gastroenterology \& hepatology, 2018. 15(5): p. 291-308.

19. Dinning, P.G., T.K. Smith, and S.M. Scott, Pathophysiology of colonic causes of chronic constipation. Neurogastroenterology and motility : the official journal of the European Gastrointestinal Motility Society, 2009. 21 Suppl 2(Suppl 2): p. 20-30.

20. Miller, M.A., et al., Comparison of scintigraphy and lactulose breath hydrogen test for assessment of orocecal transit: lactulose accelerates small bowel transit. Dig Dis Sci, 1997. 42(1): p. 10-8.

21. Ziessman, H.A., Gastrointestinal Transit Assessment: Role of Scintigraphy: Where Are We Now? Where Are We Going? Curr Treat Options Gastroenterol, 2016. 14(4): p. 452-460. 
22. Menys, A., et al., Global small bowel motility: assessment with dynamic MR imaging. Radiology, 2013. 269(2): p. 443-50.

23. Hoad, C.L., et al., Colon wall motility: comparison of novel quantitative semi-automatic measurements using cine MRI. Neurogastroenterol Motil, 2016. 28(3): p. 327-35.

24. Chaddock, G., et al., Novel MRI tests of orocecal transit time and whole gut transit time: studies in normal subjects. Neurogastroenterol Motil, 2014. 26(2): p. 205-14.

25. Weitschies, W., et al., Magnetic markers as a noninvasive tool to monitor gastrointestinal transit. IEEE Transactions on Biomedical Engineering, 1994. 41(2): p. 192-195.

26. Weitschies, W., et al., High-Resolution Monitoring of the Gastrointestinal Transit of a Magnetically Marked Capsule. Journal of Pharmaceutical Sciences, 1997. 86(11): p. 1218-1222.

27. Stathopoulos, E., et al., Magnetic pill tracking: a novel non-invasive tool for investigation of human digestive motility. Neurogastroenterology and Motility, 2005. 17(1): p. 148-154.

28. Haase, A.M., Pilot study trialling a new ambulatory method for the clinical assessment of regional gastrointestinal transit using multiple electromagnetic capsules. Neurogastroenterology and motility, 2014. 26(12): p. 1783-1791.

29. Saad, R.J., The Wireless Motility Capsule: a One-Stop Shop for the Evaluation of GI Motility Disorders. Current gastroenterology reports, 2016. 18(3): p. 14-14.

30. Maqbool, S., H.P. Parkman, and F.K. Friedenberg, Wireless capsule motility: comparison of the SmartPill GI monitoring system with scintigraphy for measuring whole gut transit. Digestive diseases and sciences, 2009. 54(10): p. 2167-2174.

31. Green, A.D., et al., Wireless Motility Capsule Test in Children with Upper Gastrointestinal Symptoms. The Journal of Pediatrics, 2013. 162(6): p. 1181-1187.

32. Sarosiek, l., et al., The assessment of regional gut transit times in healthy controls and patients with gastroparesis using wireless motility technology. Alimentary Pharmacology and Therapeutics, 2010. 31(2): p. 313-322.

33. Rao, S.S., et al., Investigation of colonic and whole-gut transit with wireless motility capsule and radiopaque markers in constipation. Clin Gastroenterol Hepatol, 2009. 7(5): p. 537-44.

34. Tran, K., R. Brun, and B. Kuo, Evaluation of regional and whole gut motility using the wireless motility capsule: relevance in clinical practice. Therapeutic advances in gastroenterology, 2012. 5(4): p. 249-260.

35. Malagelada, C., et al., New insight into intestinal motor function via noninvasive endoluminal image analysis. Gastroenterology, 2008. 135(4): p. 1155-62.

36. Malagelada, C., et al., Functional gut disorders or disordered gut function? Small bowel dysmotility evidenced by an original technique. Neurogastroenterol Motil, 2012. 24(3): p. 223-8, e104-5.

37. Malagelada, C., et al., Classification of functional bowel disorders by objective physiological criteria based on endoluminal image analysis. Am J Physiol Gastrointest Liver Physiol, 2015. 309(6): p. G413-9.

38. Karlsen, S., et al., Small intestinal transit in patients with liver cirrhosis and portal hypertension: a descriptive study. BMC gastroenterology, 2012. 12: p. 176-176.

39. Gregersen, T., et al., Effects of Sandostatin LAR on gastrointestinal motility in patients with neuroendocrine tumors. Scandinavian Journal of Gastroenterology, 2011. 46(7-8): p. 895-902.

40. Fynne, L., Gastric and smallintestinal dysfunction in spinal cord injury patients. Acta neurologica Scandinavica, 2012. 125(2): p. 123-128.

41. Hedsund, C., Gastrointestinal transit times and motility in patients with cystic fibrosis. Scandinavian journal of gastroenterology, 2012. 47(8-9): p. 920-926.

42. Fynne, L., et al., Gastrointestinal transit in patients with systemic sclerosis. Scandinavian journal of gastroenterology, 2011. 46(10): p. 1187-1193.

43. Fassov, J., et al., A randomised, controlled study of small intestinal motility in patients treated with sacral nerve stimulation for irritable bowel syndrome. BMC gastroenterology, 2014. 14: p. 111-111. 
44. Hiroz, P., et al., Colonic movements in healthy subjects as monitored by a Magnet Tracking System. Neurogastroenterology and motility : the official journal of the European Gastrointestinal Motility Society, 2009. 21(8): p. 838-e57.

45. Worsøe, J., et al., Gastric transit and small intestinal transit time and motility assessed by a magnet tracking system. BMC gastroenterology, 2011. 11: p. 145-145.

46. Rhee, P.L., et al., Analysis of pacemaker activity in the human stomach. J Physiol, 2011. 589(Pt 24): p. 6105-18.

47. Husebye, E., The patterns of small bowel motility: physiology and implications in organic disease and functional disorders. Neurogastroenterol Motil, 1999. 11(3): p. 141-61.

48. Hagger, R., et al., Periodic colonic motor activity identified by 24- $h$ pancolonic ambulatory manometry in humans. Neurogastroenterol Motil, 2002. 14(3): p. 271-8.

49. Corsetti, M., et al., First translational consensus on terminology and definitions of colonic motility in animals and humans studied by manometric and other techniques. Nat Rev Gastroenterol Hepatol, 2019. 16(9): p. 559-579.

50. Worsøe, J., et al., Turning off sacral nerve stimulation does not affect gastric and small intestinal motility in patients treated for faecal incontinence. Colorectal disease : the official journal of the Association of Coloproctology of Great Britain and Ireland, 2012. 14(10): p. e713-e720.

51. Hedsund, C., Magnet tracking allows assessment of regional gastrointestinal transit times in children. Clinical and experimental gastroenterology, 2013. 6: p. 201-208.

52. Nandhra, G.K., et al., Normative values for region-specific colonic and gastrointestinal transit times in 111 healthy volunteers using the 3D-Transit electromagnet tracking system: Influence of age, gender, and body mass index. Neurogastroenterology and motility : the official journal of the European Gastrointestinal Motility Society, 2020. 32(2): p. e13734-e13734.

53. Mark, E.B., et al., Ambulatory assessment of colonic motility using the electromagnetic capsule tracking system. Neurogastroenterology \& Motility, 2019.31(2): p. e13451.

54. Mark, E.B., Assessment of colorectal length using the electromagnetic capsule tracking system: a comparative validation study in healthy subjects. Colorectal disease, 2017. 19(9): p. 0350-0357.

55. Sutter, N., et al., Normative values for gastric motility assessed with the 3D-transit electromagnetic tracking system. Neurogastroenterology \& Motility, 2020. n/a(n/a): p. e13829.

56. Mark, E.B., et al., Ambulatory assessment of colonic motility using the electromagnetic capsule tracking system: Effect of opioids. Neurogastroenterology \& Motility, 2019.

57. Klinge, M.W., et al., Colonic motility in patients with type 1 diabetes and gastrointestinal symptoms. Neurogastroenterol Motil, 2020: p. e13948.

58. Haase, A., et al., Gastrointestinal motility during sleep assessed by tracking of telemetric capsules combined with polysomnography \&ndash; a pilot study. Clinical and Experimental Gastroenterology, 2015: p. 327.

59. Gregersen, T., Regional Gastrointestinal Transit Times in Patients With Carcinoid Diarrhea: Assessment With the Novel 3D-Transit System. Journal of neurogastroenterology and motility, 2015. 21(3): p. 423-432.

60. Haase, A.M., et al., Regional gastrointestinal transit times in severe ulcerative colitis. Neurogastroenterology \& Motility, 2016. 28(2): p. 217-224.

61. Knudsen, K., Gastrointestinal Transit Time in Parkinson's Disease Using a Magnetic Tracking System. Journal of Parkinson's disease, 2017. 7(3): p. 471-479.

62. Olesen, A.E., et al., Effects of Naloxegol on Gastrointestinal Transit and Colonic Fecal Volume in Healthy Participants Receiving Oxycodone. J Neurogastroenterol Motil, 2019. 25(4): p. 602-610.

63. Poulsen, J.L., et al., Colorectal Transit and Volume During Treatment With Prolonged-release Oxycodone/Naloxone Versus Oxycodone Plus Macrogol 3350. Journal of neurogastroenterology and motility, 2018. 24(1): p. 119-127.

64. Poulsen, J.L., et al., The Impact of Opioid Treatment on Regional Gastrointestinal Transit. Journal of neurogastroenterology and motility, 2016. 22(2): p. 282-291. 
65. Wang, Y.T., et al., Regional gastrointestinal transit and $\mathrm{pH}$ studied in 215 healthy volunteers using the wireless motility capsule: influence of age, gender, study country and testing protocol. Aliment Pharmacol Ther, 2015. 42(6): p. 761-72.

66. Cassilly, D., et al., Gastric emptying of a non-digestible solid: assessment with simultaneous SmartPill $\mathrm{pH}$ and pressure capsule, antroduodenal manometry, gastric emptying scintigraphy. Neurogastroenterol Motil, 2008. 20(4): p. 311-9.

67. Mark, E.B., et al., Assessment of colorectal length using the electromagnetic capsule tracking system: a comparative validation study in healthy subjects. Colorectal Disease, 2017. 19(9): p. 0350-0357.

68. Christodoulides, S., Multidimensional risk factor assessment in chronic idiopathic constipation, with a focus on fibre, in St Bartholomew's and the Royal London School of Medicine and Dentistry. 2019, Queen Mary University of London: London.

69. Kalsi, G.K., et al., Technical report: Inter- and intra-rater reliability of regional gastrointestinal transit times measured using the 3D-Transit electromagnet tracking system. Neurogastroenterology \& Motility, 2018. 30(11): p. e13396.

70. Stamatopoulos, K., et al., Dynamic Colon Model (DCM): A Cine-MRI Informed Biorelevant In Vitro Model of the Human Proximal Large Intestine Characterized by Positron Imaging Techniques. Pharmaceutics, 2020. 12(7).

71. Dinning, P.G., E.V. Carrington, and S.M. Scott, Colonic and anorectal motility testing in the highresolution era. Curr Opin Gastroenterol, 2016. 32(1): p. 44-8. 